MATEC Web of Conferences 47, 02008 (2016)

DOI: $10.1051 /$ matecconf/20164702008

(C) Owned by the authors, published by EDP Sciences, 2016

\title{
Prestress Loss and Bending Capacity of Pre-cracked 40 Year- Old PC Beams Exposed to Marine Environment
}

\author{
Amry Dasar ${ }^{1, a}$, Rita Irmawaty ${ }^{2}$, Hidenori Hamada ${ }^{3}$, Yasutaka Sagawa ${ }^{3}$ and Daisuke Yamamoto ${ }^{3}$ \\ ${ }^{1}$ Graduate School of Engineering, Kyushu University, 744 Motooka, 819-0395 Nishi-ku, Fukuoka, Japan \\ ${ }^{2}$ Civil Engineering Department, Hasanuddin University, Perintis Kemerdekaan KM. 10 Makassar, 90245 South \\ Sulawesi, Indonesia \\ ${ }^{3}$ Faculty of Engineering, Kyushu University, 744 Motooka, 819-0395 Nishi-ku, Fukuoka, Japan
}

\begin{abstract}
Six prestressed concrete beams (PC beam) were used for evaluation, consist of four post-tension beams (PC-O) and two pre-tension beams (PC-R). In order to investigate the effect of crack on prestress loss and bending capacity after long-term exposed, prestressed concrete beams were pre-crack and then exposed to marine environment. Experimental work was carried out to evaluate PC beams performance after long-term exposed. In addition, visual observations and load bearing capacity test was carried out. Furthermore, evaluation of prestress loss conducted using three-point loading bending test and the remaining tendon forces in the beam were determined using Crack Re-opening Method. The experimental results revealed that prestress loss was increased due to corrosion of strand/wire which affected by the pre-crack on the prestressed beams. Approximately a prestress loss around $26 \%$ and $30 \%$ was recorded for post-tension and pre-tension beams respectively.
\end{abstract}

\section{Introduction}

Reinforced concrete and prestressed concrete structures exposed to aggressive environments, cracks play an important role in accelerating the corrosion process [1]. In contrary, rather than crack widths, the surrounding concrete (i.e., concrete resistance, oxygen permeability, and chloride ion content) more contributed to the corrosion rate of steel bars in concrete, it is expected that with any size of cracks [2]. On the other hand, high strength prestressing steels show a far more sensitive reaction to corrosion attack than reinforcing bars. As the result, the loss of an equivalent sized reinforcing bar have not given a more significant effect on the structural capacity compared if the loss of one prestressing strand or wire will be. Several researchers found that corrosion of prestressing steel reduced in flexural capacity. If one $12.7 \mathrm{~mm}$ diameter prestressing strand is assumed to fail in the $100 \%$ U PS (prestressed based on nominal strengths requirements) section the nominal flexural capacity is reduced by $13.5 \%$ [3]. Furthermore, bridge was assessed to be up $10 \%$ loss in live load capacity in the individual beam which has lost the two strands [4].

\footnotetext{
${ }^{\text {a }}$ Corresponding author : amrydasar@doc.kyushu-u.ac.jp
} 


\section{Experimental Program}

\subsection{Beam details}

Six prestressed concrete beams (PC beam) were used for evaluation, consist of four post-tension beams (PC-O) and three pre-tension beams (PC-R). All the beams were cast in 1975, and have 2400 $\mathrm{mm}$ in length, with identical cross-section of $150 \times 300 \mathrm{~mm}$. Variation of bar arrangements and cover depth are adjusted to the type beam designated. Cover depths were $30 \mathrm{~mm}$ and $35 \mathrm{~mm}$ for the PC-O beams and PC-R beams respectively. Prestressing tendons were round wires of 2-2.9 $\mathrm{mm}$ in diameter with yield strengths $1148 \mathrm{~N} / \mathrm{mm}^{2}$ for PC-R beams and round bars of $17 \mathrm{~mm}$ in diameter with yield strengths $1795 \mathrm{~N} / \mathrm{mm}^{2}$ for PC-O beam respectively. Deformed bars of $10 \mathrm{~mm}$ in diameter were embedded as stirrups with spacing of $100 \mathrm{~mm}$. High early strength Portland cement was used as a cement for making concrete. The properties of the aggregate with fine-river sand (FM $=2.84$; $\mathrm{SG}=$ $2.25)$ and crushed stone $(\mathrm{FM}=6.63 ; \mathrm{SG}=2.25)$. Mix proportion of concrete was designed with water/cement ratio (w/c) and sand/total aggregate ratio (s/a) of $40.7 \%$ and $37.0 \%$, respectively. The composition of material in unit weight $\left(\mathrm{kg} / \mathrm{m}^{3}\right)$ for water, cement, sand and gravel was 167, 410, 640 and 1175 respectively [5]. The concrete was designed with a slump target of $5 \pm 1 \mathrm{~cm}$ and air content about $3 \pm 1 \%$. After placing of concrete until the start of exposed, PC beams were steam cured (max. temperature was $60^{\circ} \mathrm{C}$ ) for about 10 hours followed by curing in air after the beams were moisture cured for one day and demoulded. Prestress was introduced by the pre-tensioned method for PC-R beam and the post-tensioned method for PC-O beam. Cement paste was grouted between the bars and the sheath after post-tensioning. Also, the ends of each beam were covered with a pad of cement mortar to prevent corrosion of the ends of strands or ends anchorages.

Table 1. Summary of PC beam specimens.

\begin{tabular}{|c|c|c|c|c|c|}
\hline Beam & Type & $\begin{array}{c}\text { Cover Depth } \\
(\mathrm{mm})\end{array}$ & $\begin{array}{l}\text { Cracking } \\
\text { Condition }\end{array}$ & $\begin{array}{c}\text { Age of } \\
\text { Specimen } \\
\text { (years) }\end{array}$ & $\begin{array}{c}\text { Effective } \\
\text { Pretsress } \\
\left(\mathrm{N} / \mathrm{mm}^{2}\right)\end{array}$ \\
\hline PC-O-1 & \multirow{4}{*}{ Post-tensioning } & \multirow{4}{*}{30} & No Pre-cracked & 35 & \multirow{4}{*}{13.7} \\
\hline PC-O-2 & & & No Pre-cracked & 35 & \\
\hline PC-O-3 & & & Pre-cracked & 40 & \\
\hline PC-O-4 & & & Pre-cracked & 40 & \\
\hline PC-R-1 & \multirow{2}{*}{ Pre-tensioning } & \multirow{2}{*}{35} & No Pre-cracked & 35 & \multirow{2}{*}{$12.7-13.2$} \\
\hline PC-R-2 & & & Pre-cracked & 35 & \\
\hline
\end{tabular}

\subsection{Exposed condition}

All beams have been exposed to actual marine environments at the Sakata Port for 20 years, which is located in north-west of Japan $\left(38^{\circ} 56^{\prime} \mathrm{N}, 139^{\circ} 47^{\prime} \mathrm{E}\right)$ and faces the Sea of Japan. Two months after placing of concrete, the beams were placed in the tidal zone just in front of a caisson-type quay wall, where the beams have been subjected to wet and dry conditions alternately due to tidal action. The beams can be categorized into two conditions in term of pre-cracking, i.e. 'A' and 'B'. Condition A refers to pre-cracked, for which beams were pre-cracked by bending moment until $65 \%$ of the ultimate bending moment [6]. After cracking, the bending moment was released, and no continuous load was applied during exposed. Condition B refers to no pre-cracks. Summary of the beam specimens were presented in Table 1. After 20 years of exposed, the beams were transferred to the PARI (Port and Airport Research Institute) laboratory, stored at a constant temperature and sheltered from the rain over 15 years. Then beams were taken out to Kyushu University site for laboratory tests [7]. 


\subsection{Loading procedure}

Three-point loading with a distance of support $2100 \mathrm{~mm}$ for bending test was carried out. Bending test conducted in three separates stage was applied to each beam. In the first stage of testing, strain gauges, crack gauges and displacement transducers (LVDT, linear variable differential transformer) installed after load was applied to create and locate a series of flexural cracks. The second stage of testing conducted based on strain and displacement measurements of crack openings for the crack identified and instrumented in the first stage of testing. Then, the second stage was used in order to determine the decompression load and first cracking load in each beam. Stage three each test involved the loading until the ultimate failure reached to each beam.

\subsection{Prestress loss evaluation}

Nowadays, prestress loss can be determined analytically and experimentally. Analytically techniques such as lump-sum methods, refined or detailed methods and time-step methods. Also, there are many ways to determine the loss of prestress in experimentally. Although experimental techniques, still require a back-calculation of the prestress loss from the test data using theory of mechanics concepts. The experimentally method that will use in this research is load testing to determine crack initiation and/or crack re-opening loads to obtain the available compressive stress in the bottom flange of a member. This method is destructive test and provide information only on existing prestressing tendon stress at testing times. Some investigators define the decompression load as the load at which the first crack appears at the extreme fibers of the critical section, such us the bottom midspan fibers of a simply supported beam [8]. Then, effective prestress force $\left(\mathrm{P}_{\mathrm{e}}\right)$ was calculated by using the formula as shown as below:

$$
f=-\frac{P_{e}}{A_{C}}\left(1+\frac{e y_{t}}{r^{2}}\right)+\frac{M y_{t}}{I_{g}}
$$

where $f$ is stress at the center of gravity of prestressing force, $P_{e}$ is effective prestress after losses, $A_{c}$ is cross sectional area, $e$ is eccentricity, $y_{t}$ is neutral axis, $r^{2}$ is radius of gyration, $M$ is moment and $I_{g}$ is moment of inertia.

\section{Results and Discussion}

\subsection{Visual observation}

The cracking traces of appearance beams are shown in Figure1. Flexural crack was not found in PCO-3 although it was applied for pre-cracked before exposed. It implys that, narrower cracks heal in the natural marine environment after long-term exposed [9]. In addition, if at the flexural crack to be expected to corrosion firstly appears, the phenomenon a self-healing [10] will occurred due to slow down of chlorides migration generated from the crack filling by the corrosion products [11], and corrosion activity will be decreased [12]. This tends to prove that for longitudinal corrosion cracks, there is no self-healing as in the case of flexural cracks [13]. Moreover, longitudinal cracks pattern was found along the beams with maximum crack widths for PC-O-3 showed larger than PC-O-2 with $2.2 \mathrm{~mm}$ and $0.5 \mathrm{~mm}$, respectively. It indicates that the passive film breaks down already since the chloride threshold reached and corrosion likelihood started inspite narrower cracks healed. The cracks position showed that the crack occurred due to internal pressure resulted from corrosion of tendon. It shows that pre-cracked promote more corrosion activity and affected to increase size of crack width in spite of the fact that the tendon covered by grouted mortar and sheet. Based on JSCE standard for both type beam conditions can be categorized as second half of acceleration stage (e.g., numerous cracks 
occur due to corrosion, leaching of rust is observed, partial spalling is found and the corrosion amount of steel increased) for grades of structure appearance and deterioration state [14].

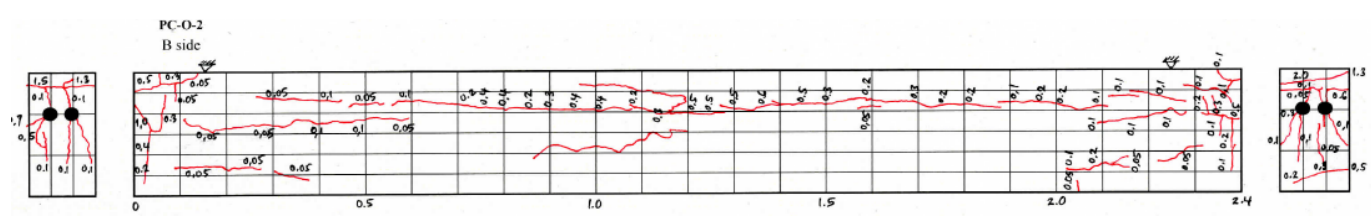

PC-O-2 (no-precrack)
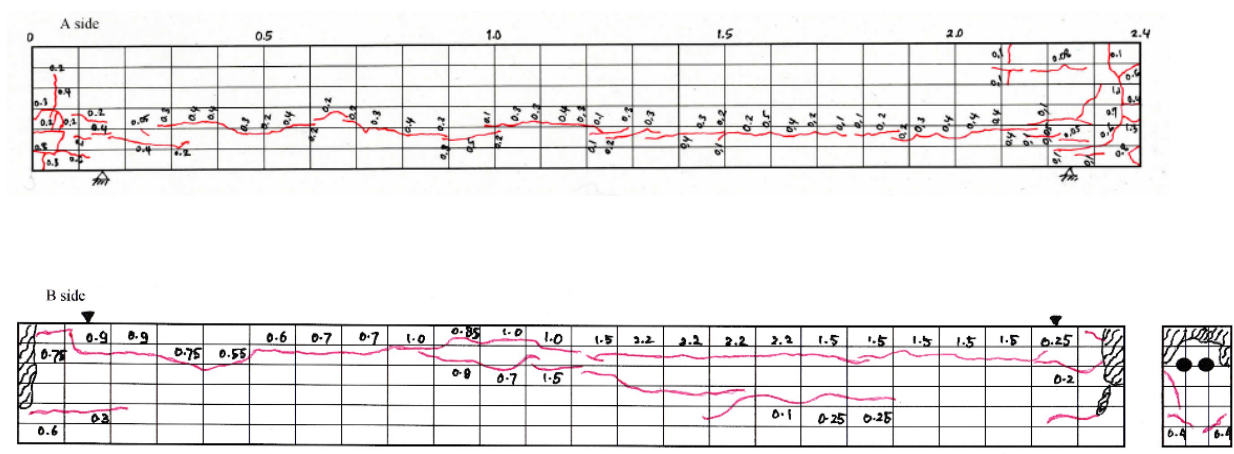

PC-O-3 (with-precrack)

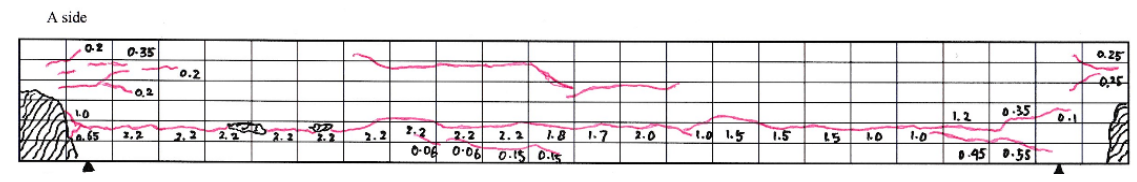

Figure 1. Crack pattern of beams over 40 years of exposed.

Extensive damage visually showed by PC-O beams compared to PC-R beams. In post-tensioned structures the anchorage zone is subdivided into the local zone and general zone, where local zone refers to the volume of concrete surrounding and immediately ahead of a mechanical anchorage device that transfers the prestress force to the member. While, pre-tensioned structures the local zone term is not applicable since these members do not contain mechanical anchorage device. The stress resulted from mechanical anchorage device perform the number of cracks in the end part of PC-O beams.

\subsection{Decompression load and prestress loss}

The decompression load was determined by intersection the two slopes of the load-strain curves. The relationship between applied load and strain is presented in Figure 2. Using the decompression load and theory of mechanics concepts then the effective prestress can be calculated (Figure 3 ). In addition, by comparing with the initial prestressing force $\left(\mathrm{P}_{\mathrm{i}}\right)$, prestress loss was calculated (Table 2). It seems that pre-cracked affected to the decompression load as the results reducing in effective prestressed. Post-tensioning and pre-tensioning beams with pre-cracked showed smaller decompression load obtained compared than without pre-cracked. This means that pre-cracked could considered to reduce decompression load about $16 \%$ for post-tensioning and $19 \%$ for pre-tensioning, respectively. The most probable explanations for above conditions are loss of bond between the strand/wire and concrete or through cracking and spalling of the concrete may give significantly affect as the result from corrosion product. Also, by introducing pre-cracked before exposed, means allow more 
aggressive agents penetrate through inside concrete and decreased life time of structure become shorter to enter deterioration stage.

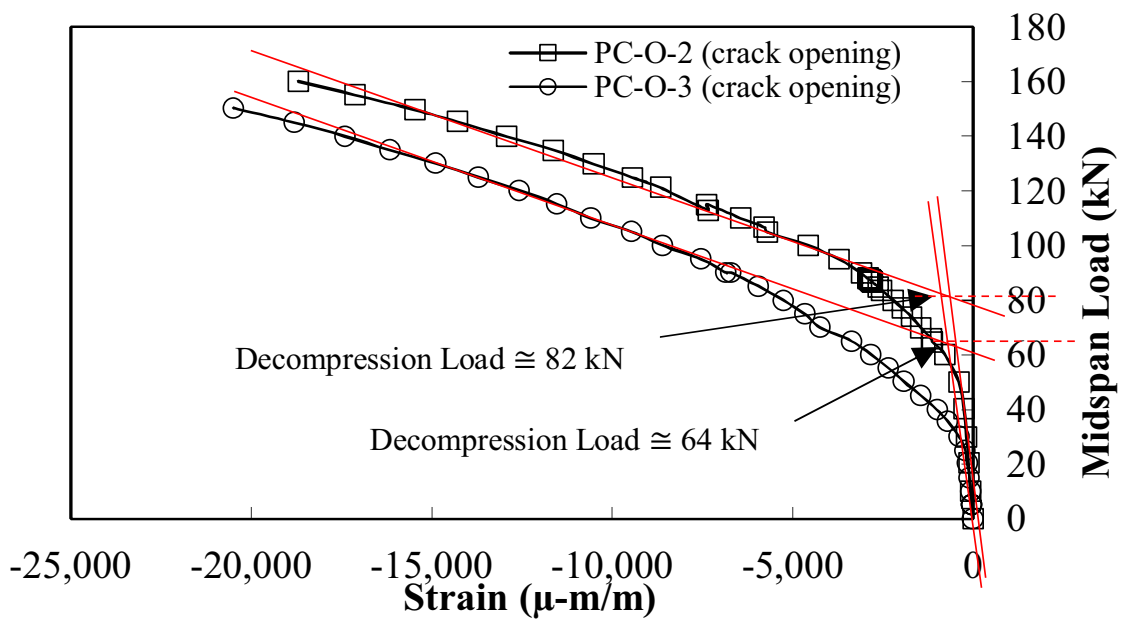

Figure 2. Determination of decompression load from the load-strain data.

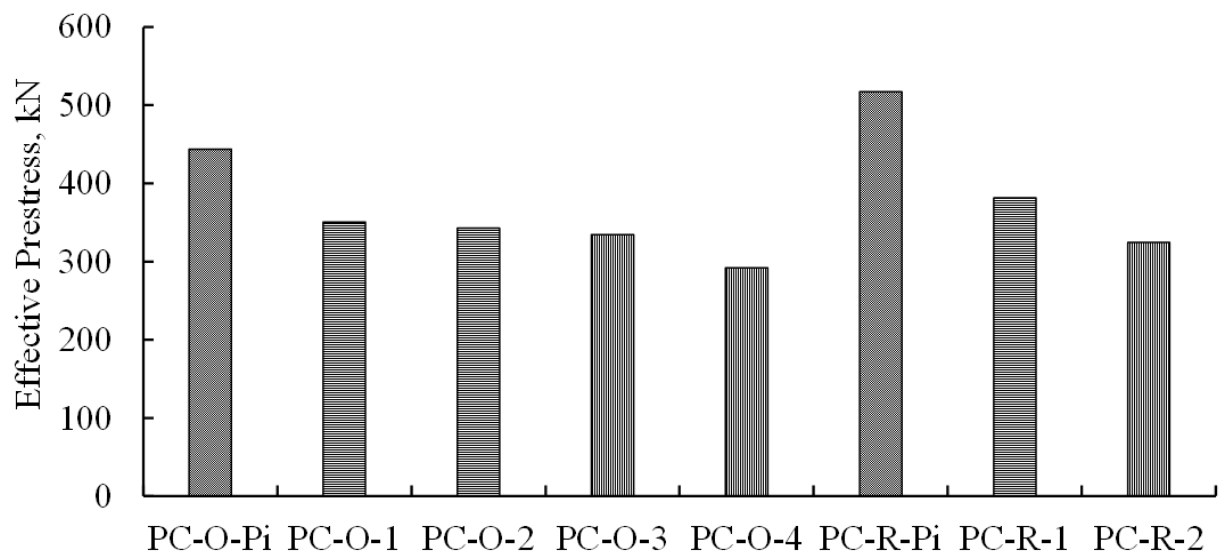

Figure 3. Effective prestress of PC beams.

The effect of pre-cracked for both PC-O and PC-R is presented in Table 2. The prestress loss increased due to pre-cracked $24 \%$ for PC-O and $31 \%$ for PC-R respectively. Post-tensioning type, precracked also contributed of prestress loss due to produce deteriorated a part of anchorage zone. During loading for pre-cracked (i.e., 0.65 ultimate moment) anchorage zone have an increasing local stress and produced numerous of crack. In addition, for post tensioning type, the anchors moved inwards during the pre-cracked, which cause a shortening of the tendon thus increasing the prestress loss. One reason of prestressed loss for pre-tension is due to the bond between wire and concrete interrupt due to pre-cracked by bending, which is produce bond loss between wire and concrete. Further, prestress loss for pre-tension type also contributed from elastic shortening due to prestressing introduced to wire before casting which cause large of prestress loss. The prestress loss perhaps may be produced by accumulative of deterioration of the beams (i.e., spalling, longitudinal cracks, anchorage zone cracks, debonding) as the result of the corrosion products. 
Table 2. Summary of several points during loading procedure.

\begin{tabular}{|c|c|c|c|c|c|c|c|}
\hline \multirow[b]{2}{*}{ Name } & \multicolumn{3}{|c|}{ Applied Load, kN } & \multirow{2}{*}{$\begin{array}{c}\text { Neutral } \\
\text { Axis, } \\
\text { mm }\end{array}$} & \multirow{2}{*}{$\begin{array}{c}\text { Initial } \\
\text { Prestress, } \\
\mathbf{P}_{\mathbf{i}}(\mathbf{k N})\end{array}$} & \multirow{2}{*}{$\begin{array}{c}\text { Effective } \\
\text { Prestress, } \\
P_{\mathrm{e}}(\mathrm{kN})\end{array}$} & \multirow{2}{*}{$\begin{array}{c}\text { Prestress } \\
\text { Loss, (\%) }\end{array}$} \\
\hline & Dec. Load & $\begin{array}{c}\text { First } \\
\text { Crack }\end{array}$ & $\begin{array}{c}\text { Ultimate } \\
\text { Load }\end{array}$ & & & & \\
\hline PC-O-1 & 80 & 92 & 215 & 22.8 & \multirow{4}{*}{443.5} & 350.8 & 20.9 \\
\hline PC-O-2 & 82 & 90 & 236 & 24.6 & & 342.8 & 22.7 \\
\hline PC-O-3 & 64 & 50 & 227 & 62.4 & & 334.8 & 24.5 \\
\hline PC-O-4 & 72 & 74 & 231 & 36.1 & & 292.0 & 34.2 \\
\hline PC-R-1 & 89 & 90 & 192 & 22.2 & \multirow{2}{*}{517.3} & 381.3 & 26.3 \\
\hline PC-R-2 & 72 & 50 & 227 & 33.2 & & 324.5 & 37.3 \\
\hline
\end{tabular}

Summary of several points during loading procedure is presented in Table 2. The first crack observed both PC-O and PC-R beams with and without pre-cracked at load $50 \mathrm{kN}$ and $90 \mathrm{kN}$ respectively. It seems that pre-cracked reduced load-carrying capacity by promote early cracks during loading. The probable explanations why specimen with pre-cracked cracks occurred earlier, because higher of prestress loss make prestressed concrete starts to behave like a reinforced concrete beam when the value of the flexural moment is well beyond the cracking moment. This explanation was linked to the neutral axis data during loading, by reduced the tensile region means crack will occurred sooner. The effect of pre-cracked reduced the effective of tensile region about $70 \mathrm{~mm}$ and $10 \mathrm{~mm}$ for $\mathrm{PC}-\mathrm{O}$ and PC-R beams respectively.

\subsection{Ultimate flexural moment capacity}

During load, flexural cracks appeared in the tension zone (i.e., both existed and new crack) and failure occurred by crushing of the concrete in the top face of compression region. Thus, the failure mode of beams was failure by bending. The ultimate flexural moment is expressed as the ratio to the initial (before exposed) flexural moment was shown in Figure 4. It seems pre-cracked affected to the flexural moment both PC-O and PC-R beams. The change of flexural moment affected due to pre-cracked about $5.58 \%$ and $4.44 \%$ for PC-O and PC-R respectively. The moment capacity decrease as loss of prestress in spite reached the large ultimate load enough. This considered performance degradation in sequence due to pre-cracked in the view point of load bearing capacity.

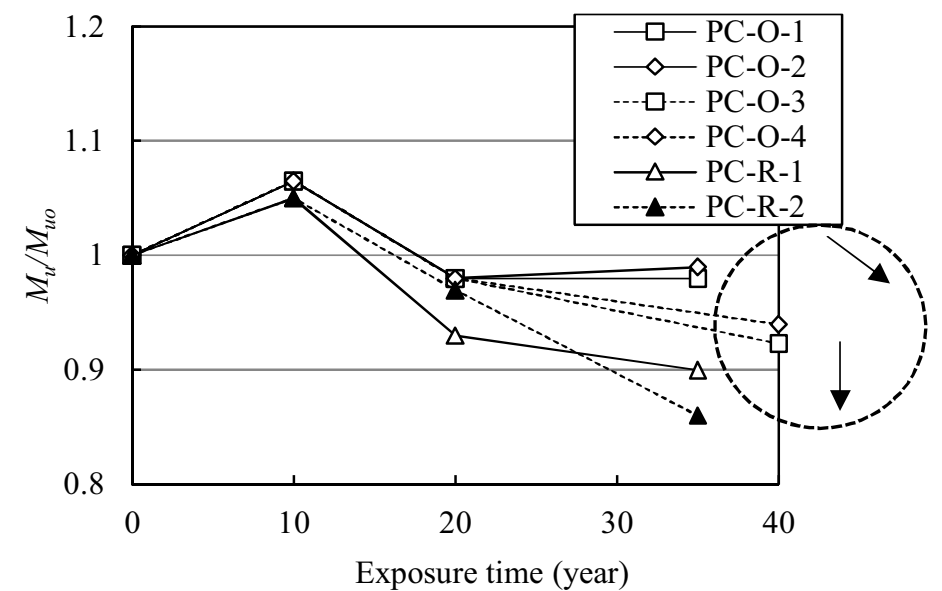

Figure 4. Change in flexural moment capacity. 


\section{Summary}

Several comprehensive test results showed that pre-cracked promote more deterioration of the beams (i.g., spalling, longitudinal cracks, anchorage zone cracks) as the result of the corrosion products. In addition, load test results of post-tensioned and pre-tensioned concrete beams with corroded tendons/wires are presented also. The prestress loss increased due to pre-cracked for PC-O and PC-R about $26 \%$ and $30 \%$ respectively. Further, change of flexural moment capacity reduced due to precracked about $5.58 \%$ and $4.44 \%$ for PC-O and PC-R consecutively. This considered degradation of structural performance contributed by pre-cracked more reasonable by increased prestress loss and reduced bending capacity

\section{Acknowledgement}

The authors thanks to PARI (Port and Airport Research Institute) for offering PC beam specimens tested in this experiment. The first author also wishes to thank Indonesia Endowment Fund for Education (LPDP) for financial support during study.

\section{References}

[1] H.S. Lopez-Calvo, T.W. Bremner, M.D.A. Thomas and P. Montes-Garcia, Effect of corrosion on tension bars in cracked HPC containing CNI, Concrete Under Severe Condition, Taylor and Francis, , 397-404, (2010).

[2] T.U. Mohammed, N. Otsuki, M. Hisada and S. Tsunenori, Effect of crack width and bar types on corrosion of steel in concrete, Material Civil Engineering, 13(3), 194-201, (2001).

[3] J.S. West, C.J. Larosche, B.D. Koester and M.E. Kreger, State of the art report about durability of post-tensioned bridge substructures, Research Report 1405 (1), The University of Texas, Austin. (1999).

[4] S.M. Bruce, P.S. McCarten, S.A. Freitag and L.M. Hasson, Deterioration of prestressed concrete bridge beams, Report of Land Transport New Zealand Research, 337, 72, (2008).

[5] H. Hamada, N. Otsuki, and M. Haramo, Durabilities of concrete beams under marine environments exposed in port of Sakata and Kagoshima (after 10 years`exposed), Technical Note of The Port and Airport Research Institute, 614, 3-43, (1988).

[6] H. Yokota, T. Fukute and H. Hamada, Structural assessment of deteriorated RC and PC beams exposed to marine environment for more than 20 years, Wakachiku Kensetsu Doboku Gijutsu Nenpo, 8, 78-84, (1999).

[7] Rita Irmawaty, A study on long-term performance of concrete over $50 \mathrm{MPa}$ in compressive strength, PhD Thesis, Kyushu University, Japan, (2013).

[8] E.G. Nawy, Prestressed Concrete: A Fundamental Approach, Prentice Hall, New Jersey, (2009).

[9] T.U. Mohammed, N. Otsuki and H. Hamada, Corrosion of steel bars in cracked concrete under marine environment, Journal of Materials in Civil Engineering, 15(5), 460-469, (2003).

[10] S. Jacobsen, J. Marchand and L. Boisvert, Effect of cracking and healing on chloride transport in OPC concrete, Cement and Concrete Research, 26(6), 869-881, (1996).

[11]C.Q. Li, Corrosion initiation of reinforcing steel in concrete under natural salt spray and service loading - results and analysis, ACI Materials Journals, 97(6), 690-697, (2000).

[12]P. Schiessl and M. Raupach, Laboratory studies and calculations on the influence of crack width on chloride-induced corrosion in concrete, ACI Materials Journals, 94(1), (1997).

[13]T. Vidal, A. Castel and R. François, Corrosion process and structural performance of a 17 year old reinforced concrete beam stored in chloride environment, Cement and Concrete Research, 37, 1551-1561, (2007).

[14]JSCE, Standard specification for concrete structures, Japan Society of Civil Engineers, (2007). 